\title{
PROTECTIVE ROLE OF BREASTFEEDING IN CHILDREN WITH CELIAC DISEASE.
}

\author{
DR. SHALMEEN TARIQ, MBBS \\ NISHTAR HOSPITAL, MULTAN, PAKISTAN.
}

DR. MARYAM ARSHAD, MBBS

NISHTAR HOSPITAL, MULTAN, PAKISTAN.

DR. GULRAIZ IQBAL, MBBS

CIVIL MEDICAL OFFICER, THQ, HOSPITAL, KAIL NEELAM, AZAD JAMMU AND KASHMIR,
PAKISTAN.

\begin{abstract}
;
Background; The prevalence of thyroid disease is likely increased among chidren with celiac disease (CD). In addition, exposure to gluten-free treatment may be associated with a risk of thyroid disease, but this association remains controversial. Objective; To Determine the frequency of Prolonged breastfeeding in children with celiac disease at a tertiary care hospital. Material and Methods; Children with celiac disease (as given in operational definition) were enrolled and their mothers was inquired regarding history of breastfeeding in their child. All the data was entered and analyzed using SPSS-18. Results; Of these 160 study cases, 67 (41.9\%) were male patients while $93(58.1 \%)$ were female patients. Mean age of our study cases was $51.19 \pm 11.25$ months (with minimum age of our study cases was 12 months while maximum age was 60 months). Of these 160 study cases, $92(57.5 \%)$ belonged to rural areas and $68(42.5 \%)$ belonged to urban areas. Monthly family income up to Rs. 35000 was noted in $68(42.5 \%)$ while more than Rs. 35000 was noted in $92(57.5 \%)$ of our study cases. Mean disease duration of celiac disease was $5.23 \pm 4.21$ months and $117(73.1 \%)$ had disease duration up to 6 months. Mean duration of breastfeeding was $18.23 \pm 5.43$ months and prolonged breastfeeding was noted in 124 (77.5\%). Conclusion; Prolonged breastfeeding frequency was poor in children with celiac disease in our study. Prolonged breastfeeding was significantly associated with age, disease duration, ethnicity and maternal literacy. A mass campaign to create awareness regarding benefits of breastfeeding should be launched at national electronic and print media. Clinicians treating children having celiac disease should educate the mothers for breastfeeding benefits so as to decrease disease morbidity which will save them future hardships and improve quality of life of such patients.
\end{abstract}

Keywords; Celiac Disease, Breastfeeding, Prolonged.

DOI: $10.7176 / \mathrm{JMPB} / 54-19$

Publication date: April $30^{\text {th }} 2019$

\section{INTRODUCTION;}

Celiac disease (CD) is a permanent immune-mediated enteropathy, triggered in genetically predisposed individuals by gluten. Gluten is a protein fraction of cereals, such as wheat, rye and barley. The genetic predisposition consists in the presence of alleles encoding for the molecules DQ2 or DQ8 of the human leucocyte antigen (HLA). ${ }^{1,2} \mathrm{CD}$ is probably the best known multifactorial disease. Genetic predisposition and gluten intake are both necessary, but not sufficient for the development of this condition. Only roughly $5 \%$ of the DQ2/8+ worldwide population will eventually develop CD. Therefore, other factors are expected to be involved in $\mathrm{CD}$ pathogenesis. Among these, additional genes are increasingly being recognised; but repeated viral infections, modality of delivery, imbalance of the intestinal microbiota and infant feeding practices have also been hypothesized. ${ }^{3,4}$ Since the use of anti-transglutaminase and anti-endomysium antibodies in the early 1990s, two main groups of clinical presentation can be identified: patients with a symptomatic form of the disease, and 
patients with a pauci (a)-symptomatic form detected during the work-up of another autoimmune disease or due to a family history of celiac disease. The prevalence of both forms of the disease is currently estimated between $1 / 100$ and $1 / 400$. Classical form of the disease is characterized by occurrence of diarrhoea, failure to thrive, and abdominal bloating in young infants in the months following gluten introduction ${ }^{5}$. Serological tests show high level of anti-transglutaminase and anti-endomysium antibodies. Until recently, the diagnosis required duodenal biopsies that show villous atrophy. HLA genotype can help for diagnosis: the absence of the HLA-DQ2 or DQ8 alleles has a high negative predictive value ${ }^{6}$. European guidelines recently proposed to reconsider the need for systematic endoscopy in typical symptomatic forms with high level of anti-transglutaminase and positive antiendomysium. These recommendations are being assessed now. Currently, the gluten-free diet remains the only effective treatment for celiac disease. Children with celiac disease have to exclude from their diet all products containing wheat, barley and rye. Gluten-free diet causes clinical remission within a few weeks, but normalization of the small bowel mucosa and negativity of anti-transglutaminase antibodies are obtained in several months or even years. Gluten-free diet is useful to obtain clinical assessment, but also to prevent longterm complications of celiac disease, mainly osteoporosis, other autoimmune diseases, decreased fertility and cancers. $^{7,8}$

Several studies have suggested a protective role of breastfeeding and/or the timing and quantity of gluten introduction in the subsequent development of celiac disease. Especially, prolonged breastfeeding during the introduction of gluten-containing feeding has been associated with a reduced risk of developing celiac disease in infancy ${ }^{9,10}$. The mentioned results suggest the existence of a 'window of opportunity' between 4 and 6 months of age in which gluten can be introduced in small amounts ${ }^{11}$. The epidemiological evidence about this strategy for the primary prevention of $\mathrm{CD}$ is conflicting and definitive recommendations on early feeding in children at genetic risk for $\mathrm{CD}$ are not available ${ }^{12}$. A study done at Karachi demonstrated frequency of breastfeeding was 88 $\%$ in children with celiac disease ${ }^{13}$. Stordel et al ${ }^{15}$ reported $81.8 \%$ prolonged breast feeding in CD.

\section{MATERIAL AND METHODS;}

Consecutive 160 children with celiac disease of either sex were enrolled from outdoor of Nishtar Hospital, Multan. Children with mental disorders, malignancies and with growth retardation were excluded from our study. Informed consent was taken from the parents of these children describing them objectives of this study, ensuring them confidentiality of the information provided and fact that there was no risk involved to the patient while taking part in this study. Children with celiac disease were enrolled and their mothers was inquired regarding history of breastfeeding in their child. All the data was entered and analyzed using SPSS-18. Descriptive statistics was applied to calculate mean and standard deviation for the age of patients, disease duration of $\mathrm{CD}$ and duration of breastfeeding. Frequencies and percentage were tabulated for the categorical variables like gender, age groups, maternal education, monthly family income, residential status, ethnicity and breastfeeding.

\section{RESULTS;}

Our study comprised of a total of 160 patients meeting inclusion criteria of our study. Of these 160 study cases, 67 (41.9\%) were male patients while $93(58.1 \%)$ were female patients. Mean age of our study cases was 51.19 \pm 11.25 months (with minimum age of our study cases was 12 months while maximum age was 60 months). Mean age of the male patients was noted to be $25.52 \pm 5.11$ months while that female patients was $48.06 \pm 13.28$ months $(\mathrm{p}=0.000)$. Our study results have indicated that majority of our study cases i.e. $147(91.9 \%)$ were more than 2.5 years. Of these 160 study cases, $92(57.5 \%)$ belonged to rural areas and $68(42.5 \%)$ belonged to urban areas. Monthly family income up to Rs. 35000 was noted in $68(42.5 \%)$ while more than Rs. 35000 was noted in $92(57.5 \%)$ of our study cases. Of these 160 study cases, 67 (41.9\%) mothers were illiterate while $93(58.1 \%)$ mothers were literate. Mean disease duration of celiac disease was $5.23 \pm 4.21$ months and $117(73.1 \%)$ had disease duration up to 6 months. Of these 160 study cases, 56 (35.0\%) were Urdu speaking, $61(38.1 \%)$ were Punjabi, 37 (23.1\%) were Saraiki and 6 (3.8\%) were Baloch. Mean duration of breastfeeding was $18.23 \pm 5.43$ months and prolonged breastfeeding was noted in $124(77.5 \%)$.

\section{DISCUSSION;}

It has long been thought that it may be possible to reduce the likelihood of celiac disease in children by prolonged breastfeeding and altering the introduction of timing of gluten to the diet of infants at risk of celiac disease. An epidemic of celiac disease among young children in Sweden during the 1980's and 1990's was 
attributed to a number of feeding practices thought to be conducive to the loss of tolerance to gluten, including a lack of breastfeeding and high gluten content during its first introduction. The notion of a "window of tolerance" was supported by a prospective cohort study that found that the risk of celiac disease was greater among infants whose first exposure to gluten occurred prior to age four months or beyond age six months. The mechanism for this "window of tolerance" was thought to be related to the relationship between gluten and the gut barrier; introduction prior to maturation of this barrier (prior to four months), or a large initial gluten load after six months, may induce innate immune activation. But the fact that these inferences were drawn from observational studies, as well as inconsistent findings regarding the protective effect of breastfeeding, left some uncertainty about the optimal approach to prevent celiac disease.

Our study comprised of a total of 160 patients meeting inclusion criteria of our study. Of these 160 study cases, 67 (41.9\%) were male patients while 93 (58.1\%) were female patients. Babar et al ${ }^{16}$ from Raheem Yar Khan also reported $60 \%$ female gender predominance which is close to our study results. Alvi et al ${ }^{17}$ from Lahore also reported 1:1.2 male to female ratio in children with celiac disease which is in compliance with our study results. A study conducted in Sukkur by Jamro et al 18 has also documented high female gender preponderance with $71 \%$ which is in compliance with our study results. Soomro et al ${ }^{19}$ from Karachi also documented male to female ratio was 1:1.4 which is in compliance with our study results.

Mean age of our study cases was $51.19 \pm 11.25$ months (with minimum age of our study cases was 12 months while maximum age was 60 months). Mean age of the male patients was noted to be $25.52 \pm 5.11$ months while that female patients was $48.06 \pm 13.28$ months $(\mathrm{p}=0.000)$. Our study results have indicated that majority of our study cases i.e. 147 (91.9\%) were more than 2.5 years. Babar et al ${ }^{16}$ from Raheem Yar Khan also reported 6.35 \pm 2.83 years mean age of the children with celiac disease which is slightly higher than our study results. The reason for this difference is due to our inclusion criteria, as we only included children up to 5 years of age maximum. Butt et al ${ }^{20}$ from Faisalabad reported 7.26 years mean age of the children with celiac disease. Alvi et al ${ }^{14}$ from Lahore also reported 6.7 years mean age. Hashmi et al ${ }^{21}$ from Lahore reported $6.67 \pm 3.35$ years mean age.

Of these 160 study cases, $92(57.5 \%)$ belonged to rural areas and $68(42.5 \%)$ belonged to urban areas. Monthly family income up to Rs. 35000 was noted in 68 (42.5\%) while more than Rs. 35000 was noted in $92(57.5 \%)$ of our study cases. Of these 160 study cases, 67 (41.9\%) mothers were illiterate while 93 (58.1\%) mothers were literate. Mean disease duration of celiac disease was $5.23 \pm 4.21$ months and $117(73.1 \%)$ had disease duration up to 6 months. Of these 160 study cases, 56 (35.0\%) were Urdu speaking, 61 (38.1\%) were Punjabi, 37 (23.1\%) were Saraiki and $6(3.8 \%)$ were Baloch.

Mean duration of breastfeeding was $18.23 \pm 5.43$ months and prolonged breastfeeding was noted in $124(77.5 \%)$. A study done at Karachi demonstrated frequency of breastfeeding was $88 \%$ in children with celiac disease ${ }^{13}$ which is close to our study results. Sajid et al ${ }^{14}$ reported $60 \%$ prolonged breastfeeding in celiac disease which is in compliance with our study results. Another study conducted in Norway by Stordel et al ${ }^{15}$ has also reported $81.8 \%$ prolonged breastfeeding which is close to our study results.

\section{CONCLUSION;}

Prolonged breastfeeding frequency was poor in children with celiac disease in our study. Prolonged breastfeeding was significantly associated with age, disease duration, ethnicity and maternal literacy. A mass campaign to create awareness regarding benefits of breastfeeding should be launched at national electronic and print media. Clinicians treating children having celiac disease should educate the mothers for breastfeeding benefits so as to decrease disease morbidity which will save them future hardships and improve quality of life of such patients.

\section{REFERENCES}

1. Sollid LM, Jabri B. Triggers and drivers of autoimmunity: lessons from coeliac disease. Nat Rev Immunol 2013;13:294-302.

2. Meresse B, Malamut G, Cerf-Bensussan N Celiac disease: an immunological jigsaw. Immunity 2012;36:907-19. 
3. Emilsson L, Magnus MC, Størdal K. Perinatal risk factors for development of celiac disease in children, based on the prospective Norwegian Mother and Child Cohort Study. Clin Gastroenterol Hepatol 2015;13:921-7.

4. Olivares M, Neef A, Castillejo G, Palma GD ${ }^{1}$, Varea $V^{3}$, Capilla $A^{4}$, et al. The HLA-DQ2 genotype selects for early intestinal microbiota composition in infants at high risk of developing coeliac disease. Gut 2015;64:406-17

5. Kaukinen K, Lindfors K, Collin P, Koskinen O, Mäki M. Coeliac disease--a diagnostic and therapeutic challenge. Clin Chem Lab Med. 2010;48(9):1205-16.

6. Ontiveros N, Hardy MY, Cabrera-Chavez F. Assessing of celiac disease and nonceliac gluten sensitivity. Gastroenterol Res Pract. 2015;2015:723954.doi: 10.1155/2015/723954

7. Norstrom F, Sandstrom O, Lindholm L, Ivarsson A. A gluten-free diet effectively reduces symptoms and health care consumption in a Swedish celiac disease population. BMC Gastroenterol. 2012;12:125.

8. Garnier-Lengliné $\mathrm{H}^{1}$, Cerf-Bensussan $\mathrm{N}^{2}$, Ruemmele $\mathrm{FM}^{3}$. Celiac disease in children. Clin Res Hepatol Gastroenterol. 2015 Oct;39(5):544-51.

9. Arigliani $\mathrm{M}^{1}$, Rech Morassutti $\mathrm{F}^{2}$, Fabris $\mathrm{M}^{3}$, Melli $\mathrm{P}^{2}$, Tonutti $\mathrm{E}^{3}$, Cogo $\mathrm{P}^{2}$. Coeliac disease in infants: antibodies to deamidated gliadin peptide come first! Ital J Pediatr. 2017 Aug 10;43(1):70. doi: 10.1186/s13052-017-0392-6.

10. Pacitto $\mathrm{A}^{1}$, Paglino $\mathrm{A}^{2}$, Di Genova $\mathrm{L}^{3}$, Leonardi $\mathrm{A}^{4}$, Farinelli $\mathrm{E}^{5}$, Principi $\mathrm{N}^{6}$, et al. Celiac Disease Presenting with Peripheral Neuropathy in Children: A Case Report. Int J Environ Res Public Health. 2017 Jul 14;14(7). pii: E785. doi: 10.3390/ijerph14070785.

11. Mearin $\mathrm{ML}^{1}$. Celiac disease: prevention in children. Dig Dis. 2015;33(2):162-6.

12. Silano $\mathrm{M}^{1}$, Agostoni $\mathrm{C}^{2}$, Sanz $\mathrm{Y}^{3}$, Guandalini $\mathrm{S}^{4}$. Infant feeding and risk of developing celiac disease: a systematic review. BMJ Open. 2016 Jan 25;6(1):e009163. doi: 10.1136/bmjopen-2015-009163.

13. Aziz S, Muzaffar R, Zafar MN, Mehnaz A, Mubarak M, Abbas Z, et al. Celiac disease in children with persistent diarrhea and failure to thrive. J Coll Physicians Surg Pak. 2007;17(9):554-7.

14. Sajid A, Ikram A, Akram I. Dietary patterns in infancy modify the risk of celiac disease. J Uni Med Dent Coll. 2014;5(1):7-12.

15. Størdal $\mathrm{K}^{1}$, White RA, Eggesbø M. Early feeding and risk of celiac disease in a prospective birth cohort. Pediatrics. 2013 Nov;132(5):e1202-9.

16. Babar MI, Ahmad I, Rao MS, Iqbal R, Asghar S, Saleem M. Celiac disease and celiac crisis in children. J Coll Physicians Surg Pak. 2011;21(8):487-90.

17. Alvi MY, Abbas M, Ahmed M, Farooq A, Kazi MY. Clinical presentation of celiac disease in children. Pak J Med Health Sci. 2010;4(4):552-4.

18. Jamro BU, Chana SM, Sankarlal SL, Jamro S. An experience of celiac disease in children at tertiary care hospital Sukkur. Rawal Med J. 2012;37(3):235-8.

19. Soomro S, Baig S, Sharafat S, Mirza T. Prevalence of Tissue Transglutamase Antibodies in cases of Celiac Disease. J Dow Uni Health Sci. 2015;9(1):9-13.

20. Butt MA, Hameed S, Bashir T, Ashraf A, Ansari Z. Clinical presentations of Coeliac disease: A prospective study. Pak J Pathol. 1998;9(3):115-20.

21. Hashmi MA, Hussain T, Masood N, Asghar RM. Diarrheal Versus Non-diarrheal Presentations of Paediatric Celiac Disease. J Coll Physicians Surg Pak. 2016;26(8):662-6. 